\title{
Reproductive biology of the Green Ground Snake Erythrolamprus poecilogyrus sublineatus (Serpentes: Dipsadidae) in Subtropical Brazil
}

\author{
FERNANDO M. QUINTELA ${ }^{1}$, WILIAM C. MARQUES ${ }^{2}$ and DANIEL LOEBMANN ${ }^{1}$ \\ ${ }^{1}$ Laboratório de Vertebrados, Universidade Federal do Rio Grande, Av. Itália, Km 8, 96203-900 Rio Grande, RS, Brazil \\ ${ }^{2}$ Instituto de Matemática, Estatística e Física, Universidade Federal do Rio \\ Grande, Av. Itália, Km 8, 96203-900 Rio Grande, RS, Brazil
}

Manuscript received on November 28, 2016; accepted for publication on February 20, 2017

\begin{abstract}
We investigated reproductive features of the dipsadid snake Erythrolamprus poecilogyrus sublineatus in the southernmost Brazilian coast, a subtropical region characterized by well-marked seasons. Females are significantly smaller than males, have a shorter tail, and reach sexual maturity at later times along their development. In contrast to tropical subspecies, E. p. sublineatus females presented a seasonal pattern, with secondary follicles occurring from late winter to early autumn and egg production restricted to the whole spring and early summer. Males presented seasonal variation in testes volume (increase in autumn and decrease in winter) while no significant seasonal variation was found in ductus deferens width. The number of oviductal eggs varied from two to nine, thus, real fecundity is also inferior than that observed in tropical E. poecilogyrus forms. Considering the thermal requirements for reproduction, it is possible that the colder climatic conditions of the southern Brazilian coast have shaped the seasonal reproductive pattern in E. p. sublineatus. The shorter body size of this subspecies may also represent a conditioning factor of low fecundity.
\end{abstract}

Key words: Ecology, neotropics, Pampa Biome, reproduction, Squamata.

\section{INTRODUCTION}

Several studies on the reproductive biology of Neotropical snakes have demonstrated a great variety of spatial/temporal patterns, many of which are strongly influenced by environmental factors (Vitt 1983, Pizzato and Marques 2006, Pizzato et al. 2007, 2008a, Marques et al. 2009, Siqueira et al. 2013, Loebens et al. 2016). Although phylogenetic relationships are a recognized determinant of

Correspondence to: Fernando Marques Quintela

E-mail: fmquintela@yahoo.com.br reproductive cycles (Seigel and Ford 1987, Barros et al. 2012,2014), investigations on species distributed over more than one single morphoclimatic domain have revealed marked geographic divergences on reproduction traits which were attributed to climatic dissimilarities between the areas occupied by the examined populations (Pizzato and Marques 2006, Leite et al. 2009, Siqueira et al. 2013).

Erythrolamprus poecilogyrus is a small-sized anurophagous dipsadid widely distributed in South America, from Venezuela and the Guyana to central Argentina (Dixon and Markezich 1992, Giraudo 
2001). Currently, four subspecies are recognized: the nominal E. p. poecilogyrus, restricted to Atlantic Forest domains in the southeastern Brazil; E. p. caesius, associated to Chaquean formations in Bolivia, Paraguay and northern Argentina; E. $p$. schotti, the most widespread subspecies, occurring from Venezuela to Corrientes and Misiones provinces of Argentina; E. p. sublineatus, restricted to the subtropical region of Rio Grande do Sul, in southernmost Brazil, up to Uruguay, Northeastern and Central Argentina (Dixon and Markezich 1992, Giraudo 2001).

Reproductive features are scarcely investigated in Erythrolamprus poecilogyrus. It is known that Erythrolamprus p. poecilogyrus from the tropical Atlantic Forest shows a continuous pattern of vitellogenic development, which was attributed to an abundance of anurans during the whole year in the studied region (Pinto and Fernandes 2004). A smaller sample of E. p. schotti from the semiarid biome of Caatinga also revealed a continuous pattern, likewise associated to anuran abundance (Vitt 1983). Herein, we investigated the reproductive biology of the southernmost distributed subspecies E. p. sublineatus, restricted to humid subtemperate/ temperate domains (Dixon and Markezich 1992). We examined the reproductive cycle, fecundity, sexual dimorphism and size at sexual maturity of specimens from the southernmost Brazilian coast, and compared such data with the previous studies on the reproductive biology of E. poecilogyrus.

\section{MATERIALS AND METHODS}

We examined 283 specimens of Erythrolamprus poecilogyrus sublineatus collected between January 2009 and August 2016 along a stretch of approximately $450 \mathrm{~km}$ of coastal plain in the Rio Grande do Sul state $\left(30^{\circ} 15^{\prime} \mathrm{S}, 50^{\circ} 29^{\prime} \mathrm{W}-33^{\circ} 38^{\prime} \mathrm{S}\right.$, $\left.53^{\circ} 17^{\prime} \mathrm{W}\right)$, in southernmost Brazil. All specimens are deposited in the herpetological collection of Universidade Federal do Rio Grande (CHFURG),
Rio Grande, Brazil (Appendix). All procedures adopted are in accordance with the institutional committee on ethics in the use of animals for research. The study area is inserted in the Pampa biome (IBGE 2004) and comprises the climate types "subtemperate humid" and "temperate humid" according to the regional classification proposed by Maluf (2000). Seasons are well-defined and rainfall is concentrated mainly in the months of winter and spring (Vieira 1984). Monthly average (grouped months) profiles of air temperatures and fluvial discharge (spatial rainfall average estimates) measured throughout the sampling period (January 2009-August 2016) in the study area are shown in Figure 1.

Snout-vent length (SVL) and tail length (TL) were measured in each specimen and a ventral incision was made from the middle of the body to around $5 \mathrm{~mm}$ above the cloaca. After sex confirmation, the significance of differences in SVL values and in tail proportion in relation to body length (ratio TL/SVL) between adult males $(n=125)$ and females $(n=99)$ was examined with a $t$ test.

The following data were obtained from females: total number of ovarian follicles, number of follicles in secondary vitellogenesis (secondary follicles), diameter of the largest secondary follicle, total number of eggs, diameter of the largest egg. The initial diameter of secondary follicles was determined based on the scatterplot of the largest follicles of all specimens (Almeida-Santos et al. 2014), which indicated a pronounced growth from $10 \mathrm{~mm}$. In recently fixed specimens, follicles with diameters around $10 \mathrm{~mm}$ or greater differed from smaller follicles due to the dark yellow coloration (see Almeida-Santos et al. 2014). Thus, follicles with diameter equal or over $10 \mathrm{~mm}$ were considered as in secondary vitellogenesis. Females were considered mature when showing at least one of the following characteristics: secondary follicles; oviductal eggs; fold oviducts, an indicative of recent 


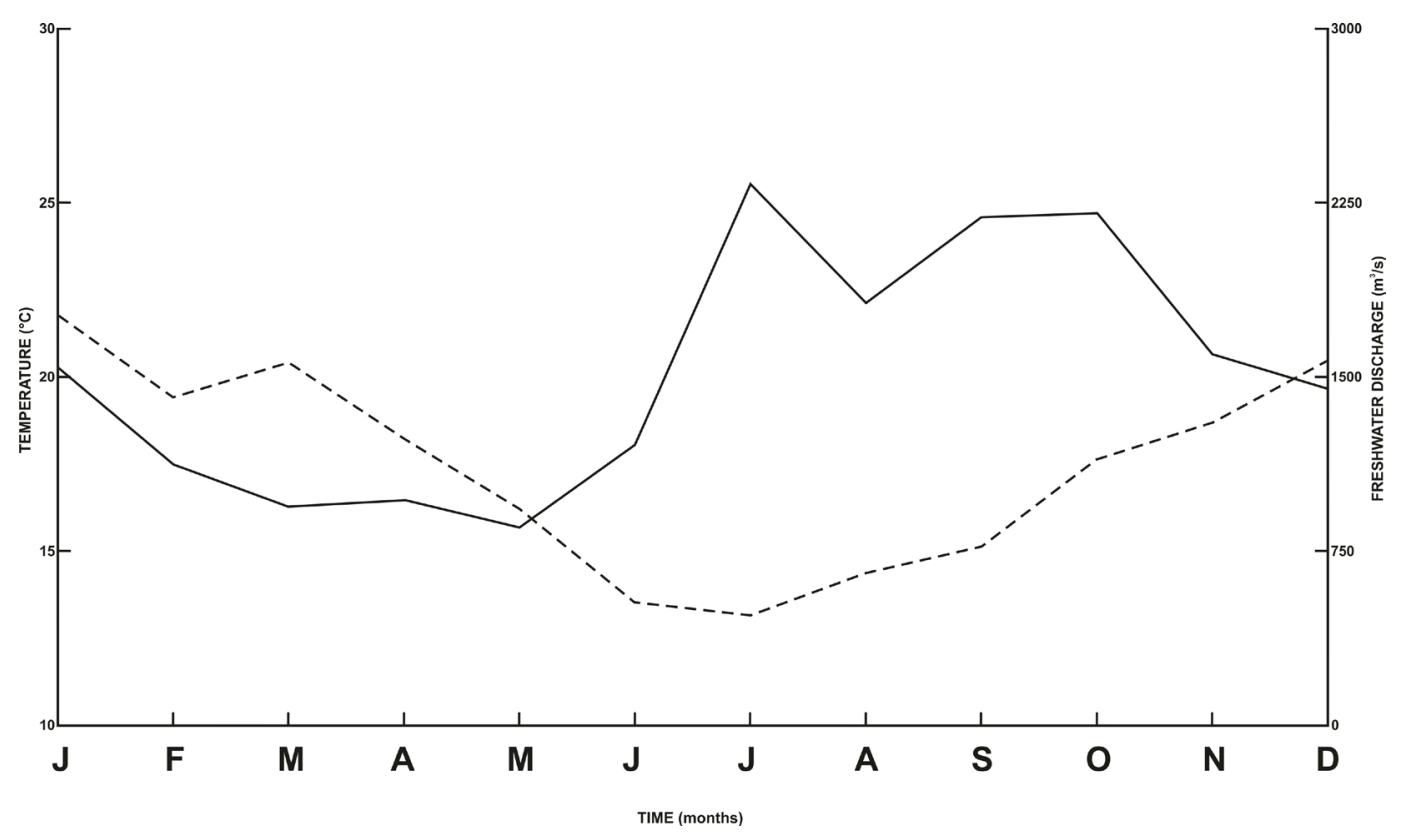

Figure 1 - Monthly average (grouped months) profiles of air temperatures (dashed line) and fluvial discharge (spatial rainfall average estimates; straight line) in the southernmost Brazilian coast throughout the sampling period of this study (January 2009-August 2016).

oviposition (Mesquita et al. 2013). The female reproductive cycle was characterized by analyses of the distribution of females with secondary follicles and/or oviductal eggs along the months of the year and from analyses of the annual profile resultant from the plot of the largest follicules/eggs of each female (Mesquita et al. 2013, Almeida-Santos et al. 2014). Fecundity was determined by the number of eggs in the oviduct (real fecundity) and number of secondary follicles (potential fecundity) (Mesquita et al. 2013). We examined the relationship between female SVL and fecundity parameters (real fecundity and potential fecundity) through a simple linear regression analysis (Siqueira et al. 2013).

Males were considered mature when presenting coiled and opaque ductus deferens, indicating the presence of sperm (Shine 1977, Almeida-Santos et al. 2014). The following measures were taken from males: length, width and thickness of the right testis; width of the distal portion of the right ductus deferens (between the kidney and the cloaca). Volume of the right testis was calculated by the ellipsoid formula $4 / 3 \pi(a / 2) \times(b / 2) \times(c / 2)$, where $a$ $=$ length, $b=$ width and $c=$ thickness (Pleguezuelos and Feriche 1999, Rojas et al. 2013). Values of testes volume and distal ductus deferens of mature males $(n=111)$ were submitted to statistical analysis. We first examined the correlation between SVL and the testes/ductus deferens variables. Since positive and moderate correlation was found between SVL and both variables (SVL/testes volume: $r=0.412$, $p<0.05$; SVL/ductus deferens width: $r=0.414, p<$ 0.05 ), we examined the occurrence of significant seasonal variation in the residuals generated by the linear regressions of testes volume and SVL and distal ductus deferens width and SVL through an analysis of variance (ANOVA). This procedure aimed to remove the effect of the specimens' body size on the seasonal variation of testes/ductus deferens dimensions (Pleguezuelos and Feriche 1999). Samples were grouped by seasons as follows: summer (January-March), autumn (AprilJune), winter (July-September), spring (OctoberDecember). Next, aiming to identify the season(s) 
with the most marked variation, we performed a post hoc Tukey test over the pairwise means of the variables. All measures were made with a digital caliper, to the nearest $0.01 \mathrm{~mm}$. Statistical analyses were performed in the software PAST, version 2.17c (Hammer et al. 2013).

\section{RESULTS}

We analyzed a total of 283 specimens (Appendix), 140 females (99 mature and 41 immature) and 143 males (125 mature and18 immature). The SVL of mature females varied from 333 to $577 \mathrm{~mm}$ (average $[X]=420 \mathrm{~mm}$; standard deviation $[s d]=56.68 \mathrm{~mm}$ ). The SVL of mature males varied from 164 to $461 \mathrm{~mm}(X=338 \mathrm{~mm} ; s d=48.78 \mathrm{~mm})$. Females, however, reached greater sizes and became sexually mature with larger size when compared to males. The values of the ratio TL/SVL indicated that males presented tails that are proportionally longer than those of females: range $=0.206-0.325$, $X=0.257, s d=0.026$; females: range $=0.175-0.286$, $X=0.229 ; s d=0.020$ ). Differences were significant both for SVL $(\mathrm{F}=1.99 ; p=0.00007)$ and the TL/SVL ratio $(\mathrm{F}=1.702 ; p=0.0148)$, when comparing sexes.

Primary follicles were found in females collected in all months while secondary follicles were found only in females collected from September to April (Figure 2). Eggs were found in 12 females collected between October and January. These results indicate a seasonal pattern for female reproduction (Mathies 2011), where the advanced stages occur during late winter, whole spring and summer, and early autumn. Secondary follicles were found throughout this period while eggs were restricted to the whole spring and early summer. Four females collected between November and January presented eggs and secondary follicles simultaneously.

The number of eggs per female (real fecundity) varied from two to nine $(X=5.16 ; s d=2.36)$. The number of secondary follicles per female (potential fecundity) varied from one to $12(X=5.87 ; s d=$ $2.80)$. The smallest females with primary follicles presented a $\mathrm{SVL}=201 \mathrm{~mm}$. The smallest female with secondary follicles showed a SVL=333 mm, while the smallest female carrying eggs showed a $\mathrm{SVL}=355 \mathrm{~mm}$. We verified a positive and moderate correlation $(r=0.44 ; p=0.012)$ between female SVL and the number of secondary follicles. On the other hand, a negative and weak correlation $(r=-0.12$; $p=0.54$ ) was found between female SVL and the number of eggs in oviducts.

Males presented the highest values of testes volume in autumn while the lowest values were recorded in the winter (Table I). The ANOVA test detected highly significant seasonal variation in residuals of testes volume $\left(F=18.65 ; p=8.369^{-10}\right)$. The post hoc Tukey test indicated highly significant differences in testes volume residuals between autumn and winter $(Q=8.119 ; p=0.00013)$, summer and winter $(Q=6.727 ; p=0.00016)$, autumn and spring $(Q=6.220 ; p=0.00027)$ and summer and spring $(Q=4.829 ; p=0.00502)$. No significant differences were found between autumn and summer $(Q=1.391 ; p=0.759)$ and winter and spring $(Q=1.898 ; p=0.538)$. The ANOVA test did not detect significant seasonal variation in the residuals of ductus deferens width $(F=1.874 ; p=0.138)$. Males with coiled and opaque ductus deferens were

TABLE I

Seasonal values of testes volume $\left(\mathrm{mm}^{3}\right)$ and width of ductus deferens $(\mathrm{mm})$ [mean \pm standard deviation (range)] of Erythrolamprus poecilogyrus sublineatus males from the southern Brazilian coast.

\begin{tabular}{|c|c|c|c|}
\hline & $\mathbf{N}$ & Testes volume & $\begin{array}{c}\text { Ductus } \\
\text { deferens width }\end{array}$ \\
\hline Summer & 15 & $\begin{array}{c}206.14 \pm 81.01 \\
(67.36-385.92)\end{array}$ & $\begin{array}{c}2.35 \pm 0.72 \\
(1.08-3.79)\end{array}$ \\
\hline Autumn & 22 & $\begin{array}{l}230.63 \pm 135.59 \\
(60.68-582.99)\end{array}$ & $\begin{array}{c}2.73 \pm 0.66 \\
(1.17-3.78)\end{array}$ \\
\hline Winter & 49 & $\begin{array}{c}122.32 \pm 46.15 \\
(29.61-227.60)\end{array}$ & $\begin{array}{c}2.72 \pm 0.61 \\
(1.11-4.01)\end{array}$ \\
\hline Spring & 22 & $\begin{array}{c}129.44 \pm 60.39 \\
(35.09-295.53)\end{array}$ & $\begin{array}{c}2.35 \pm 0.48 \\
(1.40-3.44)\end{array}$ \\
\hline
\end{tabular}




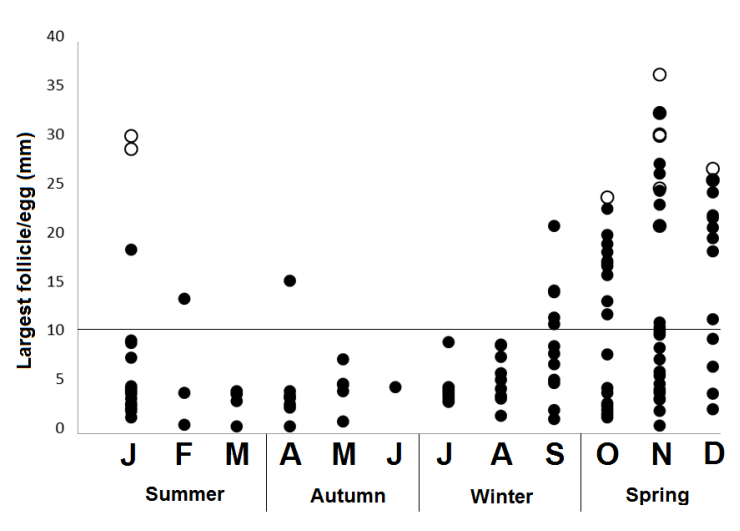

Figure 2 - Monthly variation in the diameter $(\mathrm{mm})$ of the largest follicles (black circles) and eggs (white circles) of Erythrolamprus poecilogyrus sublineatus from the southern Brazilian coast. The horizontal line indicates the size from which follicles were considered as being in secondary vitellogenesis (secondary follicles).

found in all months. The seasonal values of ductus deferens width are shown in Table I.

\section{DISCUSSION}

Erythrolamprus poecilogyrus sublineatus females reach greater sizes than males but achieve sexual maturity later along their development. The greater size of females was also observed in other subpecies of E. poecilogyrus (Dixon and Markezich 1992, Giraudo 2001, Pinto and Fernandes 2004) and seems to be a common pattern among oviparous dipsadids (Balestrin and Di-Bernardo 2005, López and Giraudo 2008, Pizzatto et al. 2008b, Orofino et al. 2010, Zanella and Cechin 2010, Mesquita et al. 2013, Panzera and Maneyro 2013). The size of the female body is associated to fecundity in such a way that larger females are able to produce larger clutches (Shine 1994, Panzera and Maneyro 2013). However, from an intraspecific viewpoint, the weak negative correlation between female SVL and clutch size in E. p. sublineatus is remarkable. This aspect may be related to the lower temperatures of subtropical domains, which may restrict the development of larger clutches even in larger females. The fact that females reach sexual maturity at later stages and larger sizes than males, which was also observed in other dipsadids (Aguiar and Di-Bernardo 2005, Zanella and Cechin 2010, Mesquita et al. 2013, Panzera and Maneyro 2013), is related to the high energetic demand for female reproduction and the necessity to reach a sufficient body size to develop a numerically viable clutch (Rivas and Burghardt 2001).

The tail in males accommodates the hemipenis and retractor muscles (King 1989) and its higher proportion in this sex seems to be a frequent condition in terrestrial dipsadids (Pizzatto et al. $2008 \mathrm{~b}$ ). The higher proportion of the tail in our male samples was unexpected, considering the conspicuously higher proportion found by Prieto et al. (2012) in females of E. p. sublineatus from northeastern Argentina. Vitt (1983) detected a slightly higher proportion in E. p. schotti females while Giraudo (2001) found no differences in a sample composed of E. p. caesius, E. p. schotti and E. p. sublineatus. The tail/snout-vent length ratio, however, seems not to represent a dimorphic character in E. poecilogyrus, seeing as it varies among subspecies and populations.

The information so far available on Erythrolamprus poecilogyrus (Vitt 1983, Pinto and Fernandes 2004; present study) indicated a plasticity regarding the female reproductive cycle and fecundity, a pattern also observed in other widespread Neotropical species such as Erythrolamprus miliaris (Pizzato and Marques 2006) and Mastigodryas bifossatus (Leite et al. 2009). Erythrolamprus p. sublineatus from the subtemperate Pampa herein analyzed presented a seasonal pattern of advanced vittelogenesis, restricted to the period ranging from late winter to early autumn. Erythrolampus. p. poecilogyrus from the tropical Atlantic Forest showed no evidence of decline in folicular production and maturation along the year (Pinto and Fernandes 2004) and E. p. schotti from the semi-arid Caatinga 
presented enlarged follicles or oviductal eggs during all seasons (Vitt 1983). This continuous reproductive pattern observed in E. p. poecilogyrus was interpreted as a response to the abundance of anurans during the whole year, along this subspecies distribution range (Pinto and Fernandes 2004). Vitt (1983) also highlights the abundance of anurans in the Caatinga and its possible role on the determination of the continuous pattern identified in E. p. schotti. Temperature is known to exert notorious influence on the female reproductive cycle of snakes (Brown and Shine 2006, Pizzato and Marques 2006, Mesquita et al. 2013), even though other environmental factors such as temporal variation of the availability of food resources for the offspring and predator densities are also involved in reproductive timing (Shine 2003). Considering the thermal requirements for vitellogenic/embriogenic development, it is plausible that the marked climatic seasonality in southernmost Brazil, with harsh temperatures during late autumn and winter (Vieira 1984), has shaped the seasonal pattern observed in E. p. sublineatus. Although anuran activity in the area decreases during cold months, most terrestrial and aquatic species can be found throughout the year (Ximenez and Tozetti 2015), which suggests that seasonal variation of food resources may not represent the conditioning factor for the temporal discontinuity in the advanced vitellogenesis of the E. p. sublineatus populations analyzed. The pattern of non-continuous or seasonal female reproduction was found in a variety of guilds and reproductive modes of populations or species from the subtropical Neotropics (Hartmann et al. 2004, Aguiar and Di-Bernardo 2005, Balestrin and DiBernardo 2005, Pizzato and Marques 2006, López and Giraudo 2008, Leite et al. 2009, Zanella and Cechin 2010, Mesquita et al. 2013, Rebelato et al. 2016), where temperature seems to represent a strong limiting factor.

An examination of the male reproductive cycle based solely on macroscopical analyses is limited to provide an accurate view of the occurring patterns (Rojas et al. 2013, Almeida-Santos et al. 2014, Braz et al. 2014). Although specimens with turgid testes and coiled/opaque ductus deferens were found during the entire year in our L. p. poecilogyrus sample, values of testes volume varied significantly between seasons, with the lowest values recorded in winter and spring. Considering that testes volume represents an indicator of spermatogenic activity (Pizzato and Marques 2006, Gribbins and Rheubert 2011), such data indicates that $E$. p. sublineatus males may reduce gametogenic processes during these seasons. Winter and early spring are marked by low temperatures in the southernmost Brazilian coast (Vieira 1984) and this condition may represent a limiting factor for gametogenesis, in view of its thermal requirements (Girons 1982). However, the confirmation of any temporal pattern of regression and recrudescence can only be inferred based on histological analyses (Rojas et al. 2013, Almeida-Santos et al. 2014). Vitt (1983) and Pinto and Fernandes (2004) show no data on the male cycle, making any intraspecific comparison impossible. Similarly to our findings, the xenodontines Lygophis anomalus (Sivan et al. 2016), Philodryas olfersii (Mesquita et al. 2013) and Philodryas patagoniensis, in subtemperate/ temperate domains (Loebens et al. 2016), show a decrease in testes volume during winter. On the other hand, no evidence of decrease in testes volume was observed in subtropical populations of the xenodontines E. miliaris (Pizzatto and Marques 2006), Thamnodynastes hypoconia (Rebelato et al. 2016) and the colubrid M. bifossatus (Leite et al. 2009).

Erythrolamprus p. sublineatus presented the lowest real fecundity among the studied $E$. poecilogyrus subspecies, showing from two to nine oviductal eggs, against three to 11 in E. p. schotti (Vitt 1983) and six to 15 in E. p. poecilogyrus (Pinto and Fernandes 2004). The higher potential fecundity observed in relation to the real fecundity 
is also noteworthy, suggesting that not all secondary follicles that are produced, are ovulated (AlmeidaSantos et al. 2014). Data on SVL from the analyzed samples of the three subspecies (Vitt 1983, Pinto and Fernandes 2004, present study) revealed $E$. p. sublineatus as the smallest form. Thus, it is possible that the smaller body size may restrict the development of larger clutches in this subspecies (Shine 1994). The presence of both oviductal eggs and secondary follicles in four females also suggests the occurrence of more than one clutch during the reproductive period. This condition was also observed in E. p. poecilogyrus (Pinto and Fernandes 2004), as well as other Neotropical dipsadids and colubrids in the subtropical domain (Pizzatto and Marques 2006, Leite et al. 2009, Mesquita et al. 2013, Panzera and Maneyro 2013) and might suggest the use of stored sperm from a single mating to the production of multiple clutches (Rojas et al. 2015).

In conclusion, reproductive parameters in $E$. poecilogyrus seem to be driven by environmental (mainly climatic) factors, in view of the divergent patterns observed in subspecies from distinct morphoclimatic domains. The lack of convergent traits, indicative of phylogenetic conservatism (Pizzatto and Marques 2006, Mesquita et al. 2013), suggests that evolutive relationships may not represent a major element in the shaping of the reproductive biology of the species.

\section{ACKNOWLEDGMENTS}

We are grateful to Coordenação de Aperfeiçoamento de Pessoal de Nível Superior (CAPES) for the postdoctoral fellowship granted to the first author; Victor Teixeira, Andressa Gomide, Pablo Borges, Felipe Caseiro, Rafael Porciuncula, and Ruth Regnet for the help in fieldwork and laboratory procedures; Rebecca Alves for language review.

\section{REFERENCES}

AGUIAR LFS AND DI-BERNARDO M. 2005. Reproduction of the water snake Helicops infrataeniatus (Colubridae) in southern Brazil. Amphibia-Reptilia 26: 527-533.

ALMEIDA-SANTOS SM, BRAZ HBP, SANTOS LC, BARROS VA, ROJAS CA AND KASPEROVICZUS KN. 2014. Biologia reprodutiva de serpentes: recomendações para a coleta e análise de dados. Herpetol Bras 3: 14-24.

BALESTRIN RL AND DI-BERNARDO M. 2005. Reproductive biology of Atractus reticulatus (Boulanger, 1885) (Serpentes: Colubridae) in Southern Brazil. Herpetol J 15: 195-199.

BARROS VA, ROJAS CA AND ALMEIDA-SANTOS SM. 2014. Is rainfall seasonality important for reproductive strategies in viviparous Neotropical pit vipers? A case study with Bothrops leucurus from the Brazilian Atlantic Forest. Herpetol J 24: 67-75.

BARROS VA, SUEIRO LR AND ALMEIDA-SANTOS SM. 2012. Reproductive biology of the neotropical rattlesnake Crotalus durissus from northeastern Brazil: A test of phylogenetic conservatism of reproductive patterns. Herpetol J 22: 97-104.

BRAZ HB, KASPEROVICZUS KN AND ALMEIDASANTOS SM. 2014. Reproductive ecology and diet of the fossorial snake Phalotris lativittatus in the Brazilian Cerrado. Herpetol J 24: 49-57.

BROWN GP AND SHINE R. 2006. Why do most tropical animals reproduce seasonally? Testing alternative hypotheses on the snake Tropidonophis mairii (Colubridae). Ecol 87: 133-143.

DIXON JR AND MARKEZICH AL. 1992. Taxonomy and geographic variation of Liophis poecilogyrus (Wied) from South America (Serpentes: Colubridae). Tex J Sci 44: 131166.

GIRAUDO A. 2001. Serpientes de la Selva Paranaense y del Chaco Húmedo. Buenos Aires: L.O.L.A., 328 p.

GIRONS HS. 1982. Reproductive cycles of males snakes and their relationships with climate and female reproductive cycles. Herpetol 38: 5-16.

GRIBBINS KM AND RHEUBERT JM. 2011. The ophidian testis, spermatogenesis, and mature spermatozoa. In: Aldridge RD and Sever DM (Eds), Reproductive Biology and Phylogeny of Snakes. Science Publishers, Enfield, p. 183-264.

HAMMER Ø, HARPER DAT AND RYAN PD. 2013. PAST: Paleontological statistics software package for education and data analysis, version $2.17 \mathrm{c}$. http://folk.uio. no/ohammer/past/. Accessed on September 14, 2016.

HARTMANN MT, MARQUES OAV AND ALMEIDASANTOS SM. 2004. Reproductive biology of the 
Southern Brazilian pitviper Bothrops neuwiedi pubescens (Serpentes, Viperidae). Amphibia-Reptilia 25: 77-85.

IBGE - INSTITUTO BRASILEIRO DE GEOGRAFIA E ESTATÍSTICA. 2004. Mapa de biomas e de vegetação [map]. http://www.ibge.gov.br/home. Acessado em 22 setembro, 2016.

KING R. 1989. Sexual dimorphism in snakes tail length: sexual selection, natural selection, or morphological constraint? Biol J Linnean Soc 38: 133-154.

LEITE PT, NUNES SF, KAEFER IL AND CECHIN SZ. 2009. Reproductive biology of the swamp racer Mastigodryas bifossatus (Serpentes: Colubridae) in subtropical Brazil. Zoologia 26: 12-18.

LOEBENS SL, CECHIN SZ, THEIS TF, MOURA LB AND ALMEIDA-SANTOS SM. 2016. Reproductive biology of Philodryas patagoniensis (Snakes: Dipsadidae) in South Brazil: male reproductive cycle. Acta Zool 1: $1-11$.

LÓPEZ MS AND GIRAUDO AR. 2008. Ecology of the snake Philodryas patagoniensis (Serpentes, Colubridae) from Northeast Argentina. J Herpetol 42: 474-480.

MALUF JR. 2000. Nova classificação climática do Estado do Rio Grande do Sul. Rev Bras Agromet 8: 141-150.

MARQUES OAV, ALMEIDA-SANTOS SM, RODRIGUES MG AND CAMARGO R. 2009. Mating and reproductive cycle in the neotropical colubrid snake Chironius bicarinatus. South Am J Herpetol 4: 76-80.

MATHIES T. 2011: Reproductive cycles of tropical snakes. In: Aldridge RD and Sever DM (Eds), Reproductive biology and philogeny of snakes. Science Publishers, Enfield, p. 511-550.

MESQUITA PCMD, SÁ-POLIDORO GL AND CECHIN SZ. 2013. Reproductive biology of Philodryas olfersii (Serpentes, Colubridae) in a subtropical region of Brazil. Herpetol J 23: 39-44.

OROFINO RP, PIZZATTO L AND MARQUES OAV. 2010. Reproductive biology and food habits of Pseudoboa nigra (Serpentes: Dipsadidae) from the Brazilian Cerrado. Phyllomedusa 9: 53-61.

PANZERA A AND MANEYRO R. 2013. Reproductive biology of the snake Liophis anomalus (Günther, 1858, Dipsadidae, Xenodontinae). Herpetol J 23: 81-87.

PINTO RR AND FERNANDES R. 2004. Reproductive biology and diet of Liophis poecilogyrus poecilogyrus (Serpentes, Colubridae) from southeastern Brazil. Phyllomedusa 3: 9-14.

PIZZATTO L, ALMEIDA-SANTOS SM AND MARQUES OAV. 2007. Biologia reprodutiva de serpentes brasileiras. In: Nascimento LB and Oliveira ME (Eds), Herpetologia no Brasil II. Sociedade Brasileira de Herpetologia, Belo Horizonte, p. 201-221.

PIZZATO L, CANTOR M, OLIVEIRA JL, MARQUES OAV, CAPOVILLA V AND MARTINS M. 2008b.
Reproductive ecology of snakes of the tribe Dipsadini. Herpetologica 64: 168-179.

PIZZATO L, JORDÃO RS AND MARQUES OAV. 2008a. An overview of reproductive strategies in Xenodontini (Serpentes: Colubridae: Xenodontinae) with new data for Xenodon neuwiedii and Waglerophis merremii. J Herpetol 42: 153-162.

PIZZATO L AND MARQUES OAV. 2006. Interpopulational variation in reproductive cycles and activity of the water snake Liophis miliaris (Colubridae) in Brazil. Herpetol $\mathrm{J}$ 16: 353-362.

PLEGUEZUELOS JM AND FERICHE M. 1999. Reproductive ecology of the horseshoe whip snake, Coluber hippocrepis, in the southeast of the Iberian Peninsula. J Herpetol 33: 202-207.

PRIETO YA, GIRAUDO AR AND LÓPEZ MS. 2012. Diet and sexual dimorphism of Liophis poecilogyrus (Serpentes, Dipsadidae) from the wetlandregions of northeast Argentina. J Herpetol 46: 402-406.

REBELATO MM, PONTES GMF AND TOZETTI AM. 2016. Reproductive biology of Thamnodynastes hypoconia (Serpentes: Dipsadidae) in Brazilian subtemperate wetlands. An Acad Bras Cienc 88: 1699-1709.

RIVAS JA AND BURGHARDT GM. 2001. Understanding sexual size dimorphism in snakes: wearing the snakes's shoes. Anim Behav 62: 1-6.

ROJAS CA, BARROS VA AND ALMEIDA-SANTOS SM. 2013. The reproductive cycle of the male Sleep Snake Sibynomorphus mikanni (Schlegel, 1837) from southeastern Brazil. J Morphol 274: 215-228.

ROJAS CA, BARROS VA AND ALMEIDA-SANTOS. 2015. Sperm storage and morphofunctional bases of the female reproductive tract of the snake Philodryas patagoniensis from southeastern Brazil. Zoomorphology 134: 1-10.

SEIGEL R AND FORD N. 1987. Reproductive ecology. In: Seigeil R et al. (Eds), Snakes: Ecology and Evolutionary Biology: MacMillan Publish Co., New York, p. 210-252.

SHINE R. 1977. Reproduction in Australian elapid snakes. I. Testicular cycles and mating seasons. Aust J Zool 25: 647-653.

SHINE R. 1994. Sexual dimorphism in snakes revised. Copeia 1994: 326-346.

SHINE R. 2003. Reproductive strategies in snakes. Proc R Soc B, Biol Sci 270: 995-1004.

SIQUEIRA DM, NASCIMENTO LP, MONTINGELLI GG AND SANTOS-COSTA MC. 2013. Geographical variation in the reproduction and sexual dimorphism of the Boddaert's tropical racer, Mastigodryas boddaerti (Serpentes: Colubridae). Zoologia 30: 475-481.

SIVAN J, PANZERA A AND MANEYRO R. 2016. Male reproductive cycle of a Neotropical snake, Lygophis anomalus (Dipsadidae), in a temperate geographic distribution. South Am J Herpetol 11: 114-118. 
VIEIRA EF. 1984. Rio Grande do Sul: geografia física e vegetação. Sagra: Porto Alegre, 184 p.

VITT LJ. 1983. Ecology of an anuran-eating guild of terrestrial tropical snakes. Herpetologica 39: 52-66.

XIMENEZ SS AND TOZETTI AM. 2015. Seasonality in anuran activity and calling season in a Brazilian subtemperate wetland. Zool Stud 54: 47.

ZANELLANAND CECHIN SZ. 2010. Reproductive biology of Echinanthera cyanopleura (Serpentes: Dipsadidae) in southern Brazil. Zoologia 27: 30-34.

\section{APPENDIX}

Specimens examined from the herpetological collection of Universidade Federal do Rio Grande (CHFURG):

Brazil: Rio Grande do Sul: Palmares do Sul (CHFURG 2553); São José do Norte (CHFURG 1948); Rio Grande, Ilha do Leonídeo (CHFURG 3275, 3326, 3435, 3436, 3437), Quinta (CHFURG 2226, 2876, 3438, 3439, 3440, 3441), Ilha dos
Marinheiros (CHFURG 1633), Barra (CHFURG 1631, 1793), Cassino (CHFURG 830,959, 961, 962, 963, 964, 965, 966, 968, 969, 970, 971, 972, 976, 977, 978, 980, 981, 986, 987, 988, 989, 990, 991, 994, 995, 996, 997, 1004, 1005, 1006, 1007, 1629, 2372, 3320, 3321, 4380, 4404, 4405, 4415, 4417, 5041, 5046, 5048, 5050, 5088, 5138, 5139, 5140, 5142, 5144, 5146, 5147, 5148), Carreiros (CHFURG 1673, 1794, 2544, 2691, 2778, 2820, 2836, 2962, 2980, 3135), Senandes (CHFURG $768,1025,1256,1260,2988)$, Distrito Industrial (CHFURG $1264,1626,1628,1632,1639,1646,1671,1674,1675$, $1698,1786,1802,1804,1949,2228,3091,3112,3157,3160$, 3323, 3324, 3401, 3402, 3409, 3410, 3413, 3414, 3416, 3417, 3419, 3420, 3422, 3434, 3442, 3443), Taim (CHFURG 887, 984, 1037, 1074, 1268, 1269, 1270, 1442, 1443, 1444, 1445, $1463,1464,1540,1729,1730,1731,1732,1733,1734,1787$, 2147, 2314, 2508, 2510, 2511, 3137, 3139, 3140, 3143, 3144, 3403, 3404, 3406); Santa Vitória do Palmar, Hermenegildo (CHFURG 2024). 